\title{
Bilateral Tuberculous Otitis Media: A Rare Presentation
}

\author{
Honnurappa Vijayendra ${ }^{1}$ Nilesh Mahajan ${ }^{1}$ Vinay Vijayendra ${ }^{1}$
}

${ }^{1}$ Vijaya ENT Care Centre, Super Speciality Otology Centre, Bangalore, Karnataka, India

Ann Otol Neurotol ISO 2018;1:43-48
Address for correspondence Vijayendra Honnurappa, DLO, MS, Vijaya ENT Care Centre, No.1, 9th Cross, Malleshwaram, Bangalore 560003, Karnataka, India (email id: vijayentblr@gmail.com)

\begin{abstract}
Keywords

- tuberculous otitis media

- AKT4

- AKT3

- INDEX-TB guidelines

Introduction Tuberculosis is one of the most common infectious diseases in India. Tuberculosis of the middle ear is rare, usually seen in association with pulmonary tuberculosis or in patients with history of pulmonary tuberculosis. It is an uncommon and frequently misdiagnosed form of tuberculosis. In our experience, we have seen $50 \%$ of cases of tuberculous otitis media without pulmonary tuberculosis. These cases presented with rapid deterioration of hearing with more sensorineural component in hearing loss.

Case Report This is a case report of 34-year-old woman presented to us with worsening of hearing over short duration of 3 months. She developed right profound hearing loss and left moderately severe mixed hearing loss, which deteriorated within duration of 2 weeks. Very few cases have been reported in literature affecting both the ears. In our experience, we have seen seven such cases with bilateral ear involvement.

Conclusion Tuberculosis of the middle ear is a rare condition. For complete cure, medical therapy should be given at least for 9 months including 2 months 4 tablets (AKT4) and 7 months 3 tablets (AKT3) regimes, according to the INDEX-TB guidelines provided by government of India for extrapulmonary tuberculosis. Surgical treatment should be always added as emergency to prevent progression of sensorineural hearing loss and in cases of complications such as facial palsy.
\end{abstract}

\section{Introduction}

Tuberculosis is one of the most common infectious diseases in India. Tuberculosis of the middle ear is rare usually seen in association with pulmonary tuberculosis or in patients with history of pulmonary tuberculosis. It is an uncommon and frequently misdiagnosed form of tuberculosis. ${ }^{1}$ The involvement of the temporal bone in tuberculosis was first described by Jean Louis Petit in 18th century. ${ }^{2}$ Wilde $^{3}$ in 1853 described the clinical features of tuberculous otitis media. Koch demonstrated tuberculous bacillus in 1882 . After just 1 year in 1883, Esche isolated tuberculous bacillus in the secretion of the middle ear. ${ }^{4,5}$ Primary tuberculosis of the ear has rarely been reported as the disease is usually secondary to infection in the lungs, pharynx, larynx, and nose. ${ }^{6,7}$ In our experience, we have seen $50 \%$ of cases of tuberculous otitis media without any history of pulmonary tuberculosis. Typical features include painless otorrhea, multiple perforations, and pale granulations. In our experience, we have seen cases of tuberculous otitis media with rapid deterioration of hearing with more sensorineural component in hearing loss.

\section{Case Report of Bilateral Tuberculous Otitis Media}

A 34-year-old woman presented with bilateral hard of hearing and blocking sensation since 3 months. She noticed rapid deterioration in hearing over a short period of 2 weeks, and hence she ca for consultation. She was unable to hear normal conversation as well as loud voices and was unable to communicate over mobile phone. On clinical examination, bilaterally tympanic membrane was dull pale with definite bulge on right side pushing handle of malleus laterally and on left side was mimicking otitis media with effusion (-Figs. 1 and 2). On Valsalva maneuver and 


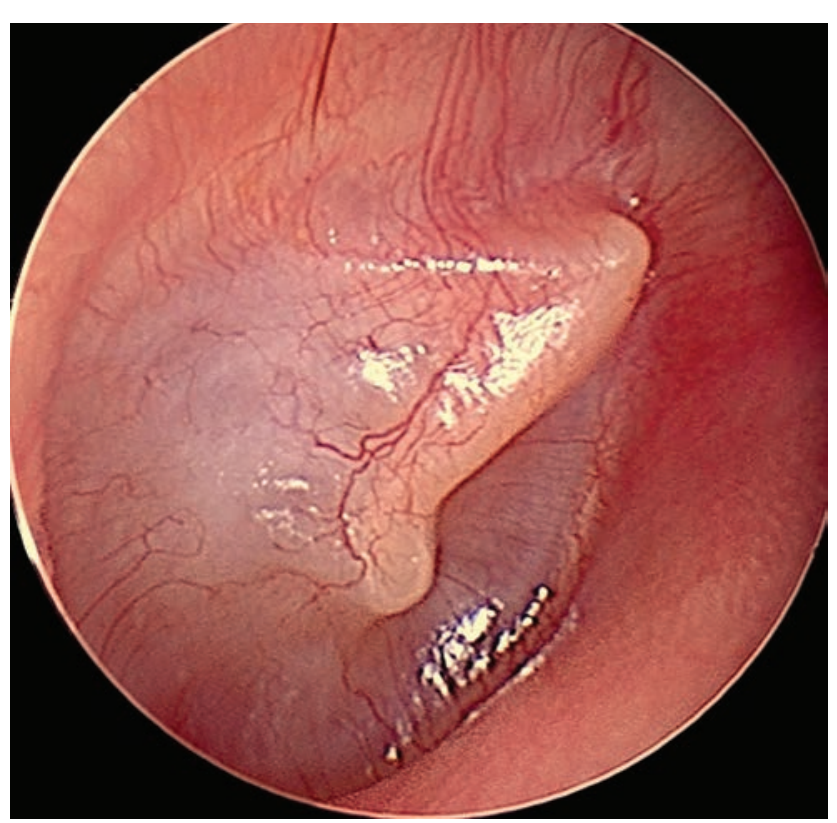

Fig. 1 Bulging TM with lateralized HOM. HOM, handle of malleus.

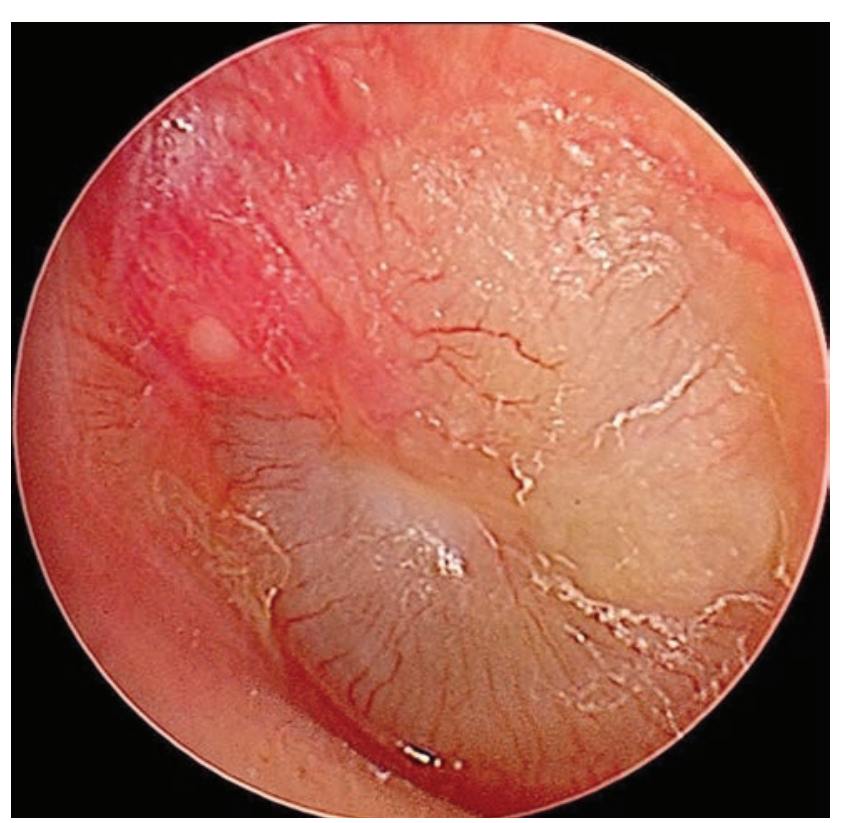

Fig. 2 TM mimicking OME. OME, otitis media with effusion.

seigelization, movement of the tympanic membrane was seen to be absent on both the sides.

Audiometry showed right profound mixed hearing loss (95 dB) and left moderately severe mixed hearing loss (61 dB), and tympanometry showed type B tympanogram ( - Fig. 3 ).

Laboratory studies showed white blood cell count of $10,900 / \mathrm{mm}^{3}$ with $54.2 \%$ neutrophils, $34.6 \%$ lymphocytes, $8.3 \%$ monocytes, $2.7 \%$ eosinophils, and $0.2 \%$ basophils.

Hemoglobin was $13.3 \mathrm{~g} \%$ with negative antiretroviral test. Erythrocyte sedimentation rate was $34 \mathrm{~mm}$ in first hour. Blood sugar level was $85 \mathrm{mg} / \mathrm{dL}$. Platelet count was $272,000 / \mathrm{mm}^{3}$. Mantoux test was strongly positive, and X-ray chest was normal.

Myringotomy was done to take biopsy from the middle ear and to drain fluid inside, if any. On myringotomy, in the middle ear, there was no fluid on right side and minimal fluid was aspirated from left side; instead, pale-colored extensive granulations were present. Biopsy was taken from these granulations from both the sides and sent for histopathologic examination (HPE) separately. Both the sides showed Langhans'-type giant cells and foci of caseous necrosis consistent with diagnosis of tuberculosis.

Then the patient was subjected to high-resolution computed tomography (HRCT) of the temporal bone to see extent of the soft tissue in middle ear cleft. Entire middle ear cavity on both the sides was seen to be filled with soft tissue without any ossicular destruction. Mastoid cavity was also seen to be partly occupied by soft tissue, but bony septa were intact (-Fig. 4).

The patient was put on 2 months 4 tablets (AKT4) regime immediately on receiving the histopathologic report after myringotomy. As the patient developed progressive hearing loss, on emergency basis exploration was done. Both side mastoidectomy with type I tympanoplasty done on 2 successive days. Mastoid cavity was pneumatic with antrum seen to be blocked by extensive pale granulation tissue; hence, patency was not there. After elevation of flaps, entire middle ear cavity was seen filled with extensive pale granulation tissue extending and blocking eustachian tube orifice and encasing and embedding whole ossicular chain within it. Granulation tissue meticulously was cleared from entire middle ear cavity retaining the intact ossicular chain and sent for HPE. Antrum cleared of all granulation tissue and patency established. On both the sides, granulation tissue was encasing ossicular chain, restricting its mobility. All the granulation tissue meticulously cleared and good ossicular mobility established. Round window reflex elicited. On both the sides, type I tympanoplasty was done using underlying of temporalis fascia graft and exteriorization of handle of malleus done (-Figs. 5-10).

Biopsy once again confirmed Langhans'-type giant cells, epithelioid cell granuloma, and foci of caseating necrosis consistent with diagnosis of tuberculosis (-Fig. 11).

The patient was advised AKT for 9 months as per INDEX-TB guidelines provided by the government of India for extrapulmonary tuberculosis of which she completed AKT4 for 2 months and is currently on AKT3 since 1 month (to be taken for total 7 months). On postoperative 1 month, audiometry test showed improvement in hearing, which was again repeated after 3 months showing consistent improvement in hearing. Both sides air conduction and bone conduction thresholds improved ${ }^{8}$ (right $83 \mathrm{~dB}$, left $51 \mathrm{~dB}$; - Fig. 12).

\section{Discussion and Conclusion}

Tuberculosis of the middle ear is rare condition. Very few cases have been reported to involve temporal bone and bilateral pathology is rarest. Tuberculosis of the middle ear is most commonly seen in patients with previous history of tuberculosis in the lungs. In our experience, we have seven cases of bilateral tuberculous otitis media. Three mechanisms explaining middle ear tuberculosis infection have been postulated. First is aspiration of mucus through 


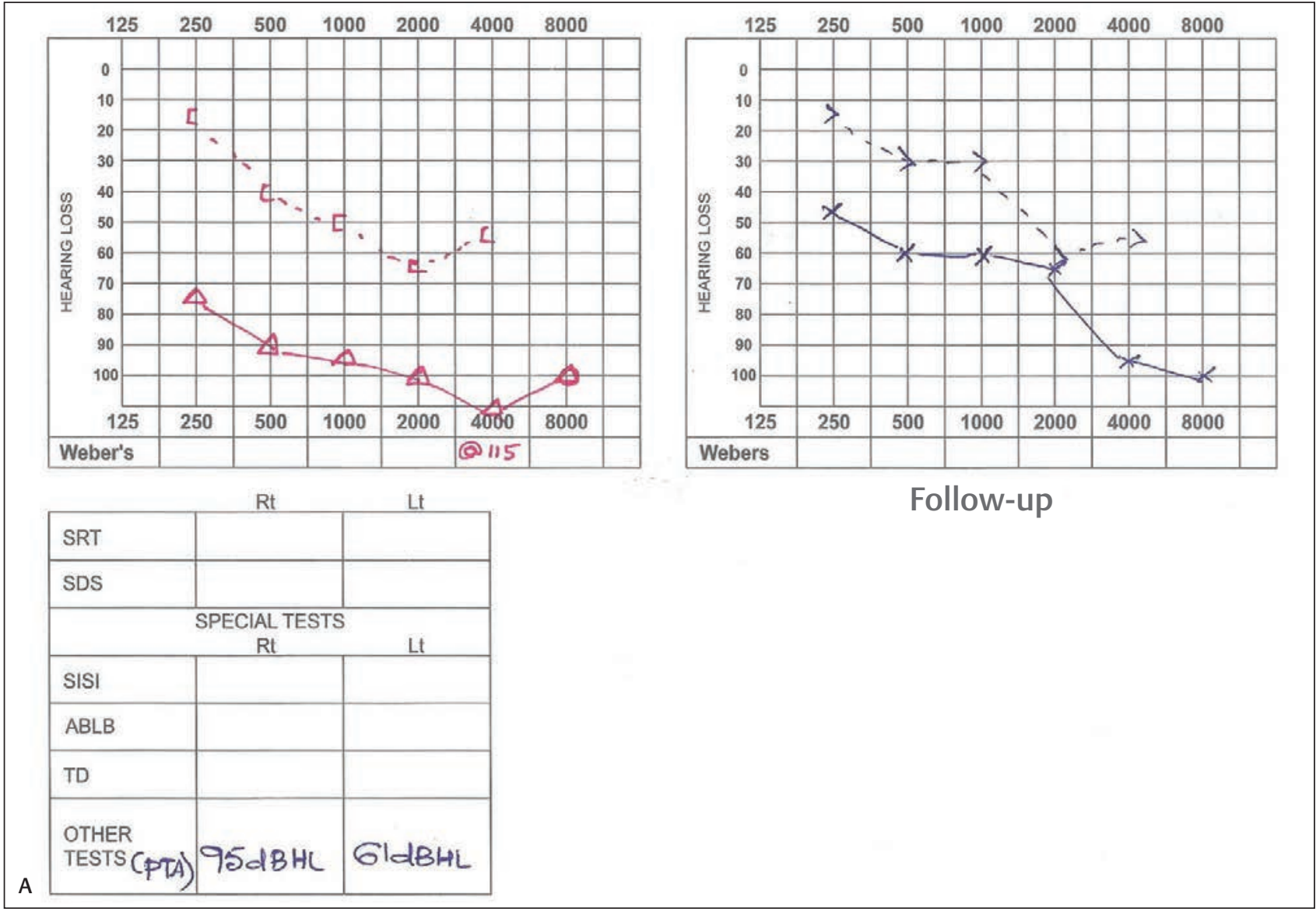

\section{$226 \mathrm{~Hz}$ Tympanogram}

\section{Right}
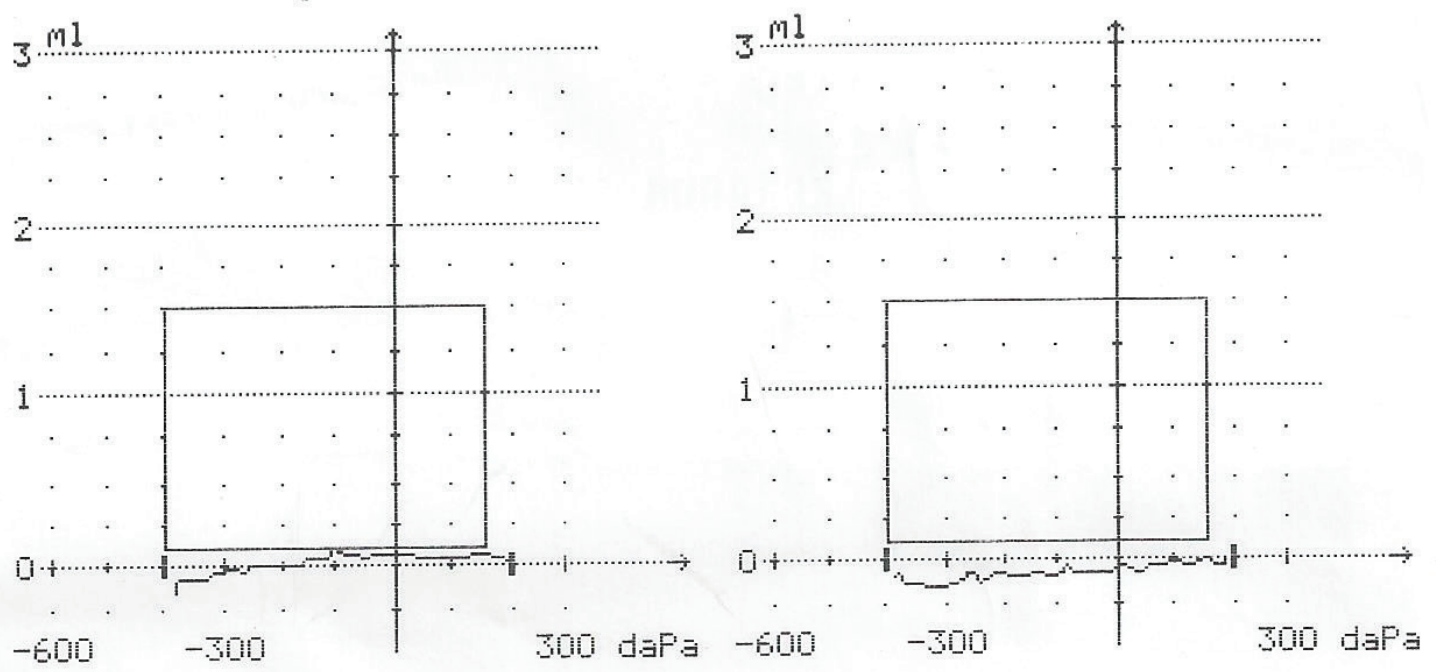

$$
\begin{aligned}
& \text { Eat volume 0.57 ml } \\
& \text { Compliance } 0.09 \mathrm{ml} \\
& \text { Fresente -104 daFe } \\
& \text { Gradient }
\end{aligned}
$$
Ear Uolume
3. $11 \mathrm{ml}$
Compli ance
$0.00 \mathrm{ml}$
Frescure
[ $\mathrm{d}: \mathrm{F}:$
Gradient
$41 \mathrm{dgF}:=$ 

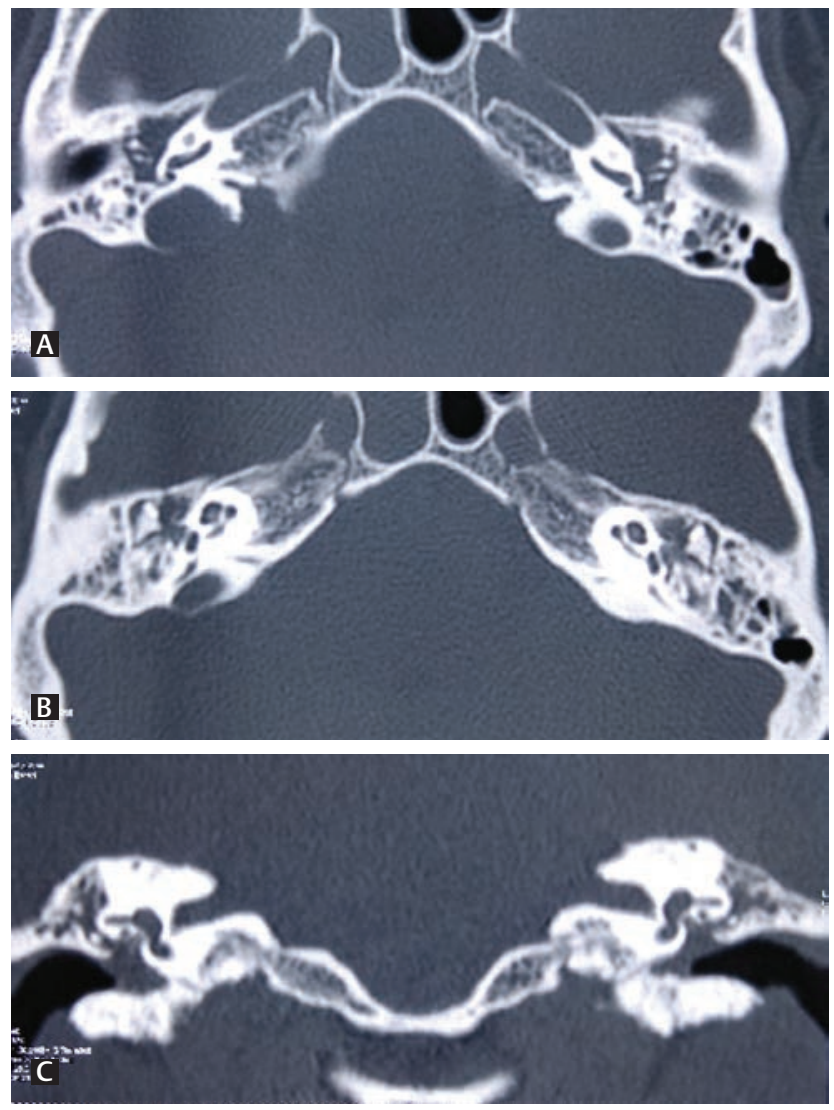

Fig. 4 High-resolution computed tomography temporal bone showing soft tissue in middle ear (A), epitympanum and partly in mastoid cavity with mastoid septa intact (B, C).

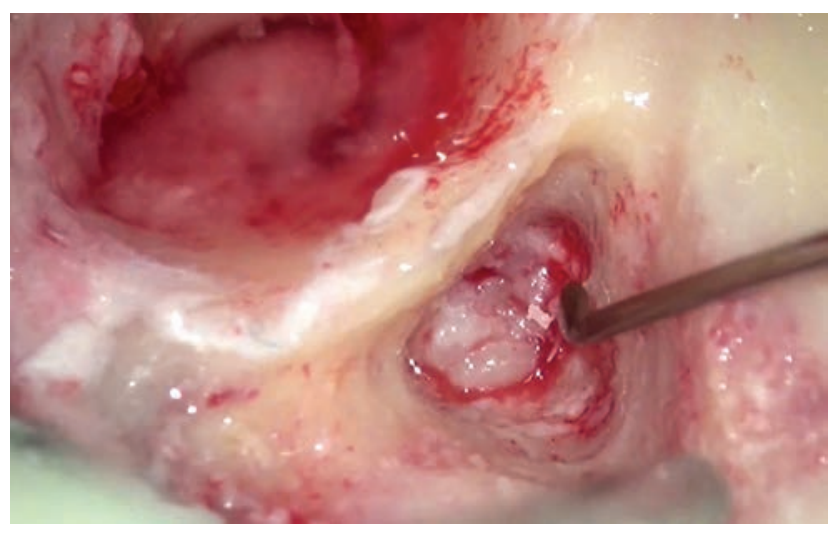

Fig. 5 Pale granulations in antrum.

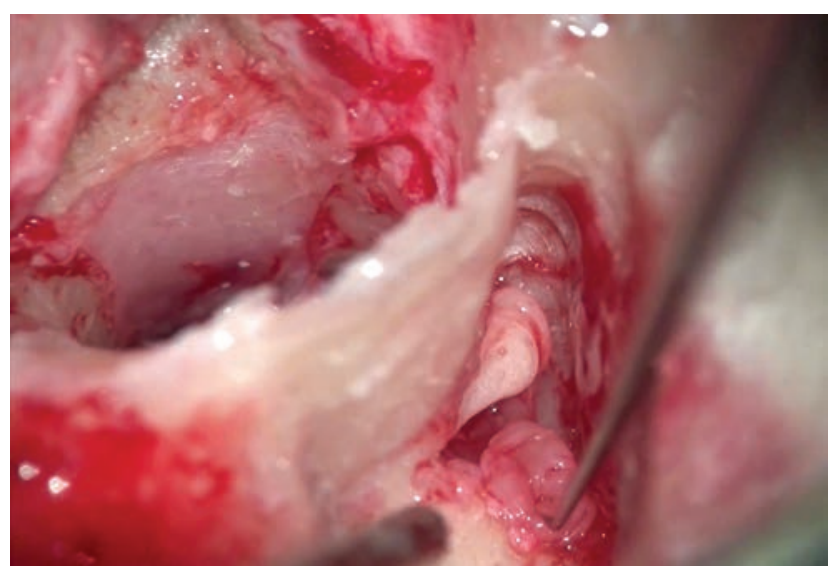

Fig. 6 Granulations cleared (epitympanotomy).

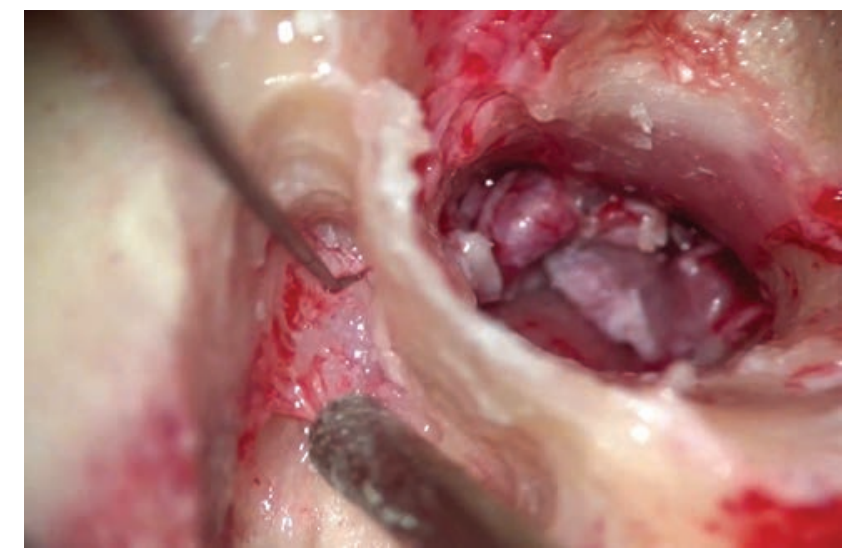

Fig. 7 Pale granulations in antrum.

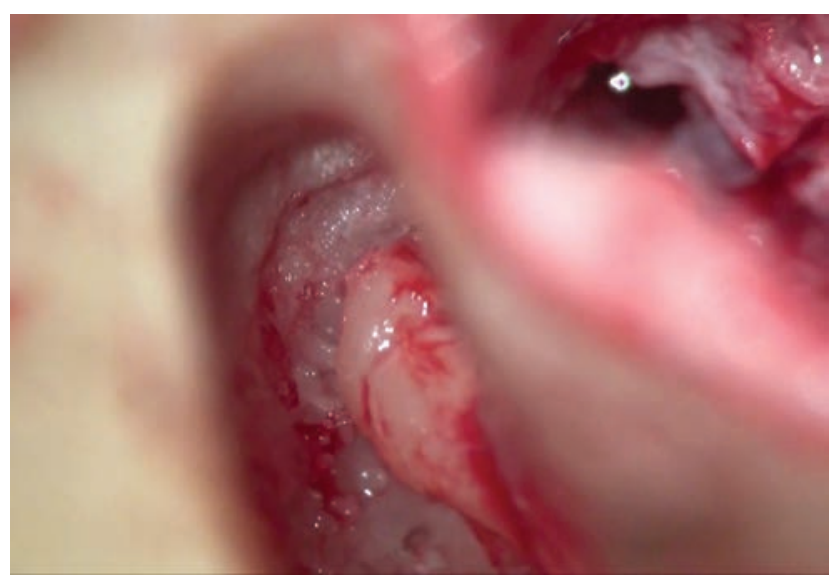

Fig. 8 Granulations cleared (epitympanotomy).

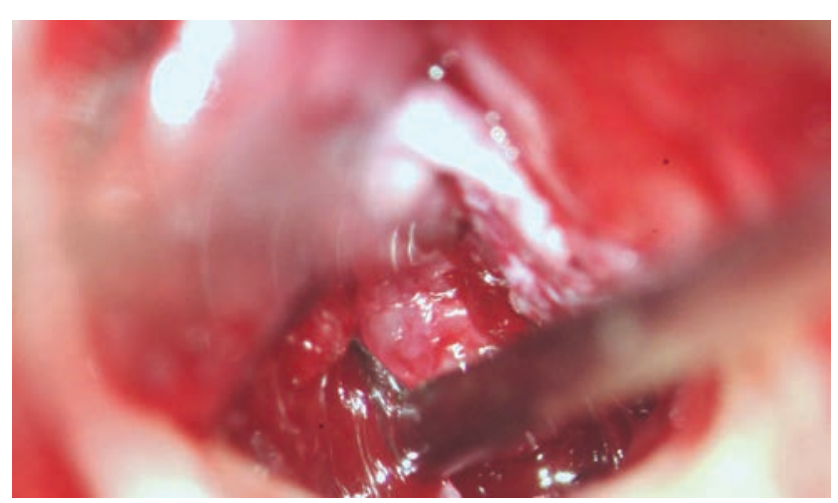

Fig. 9 Extensive granulations in ME. ME, middle ear.

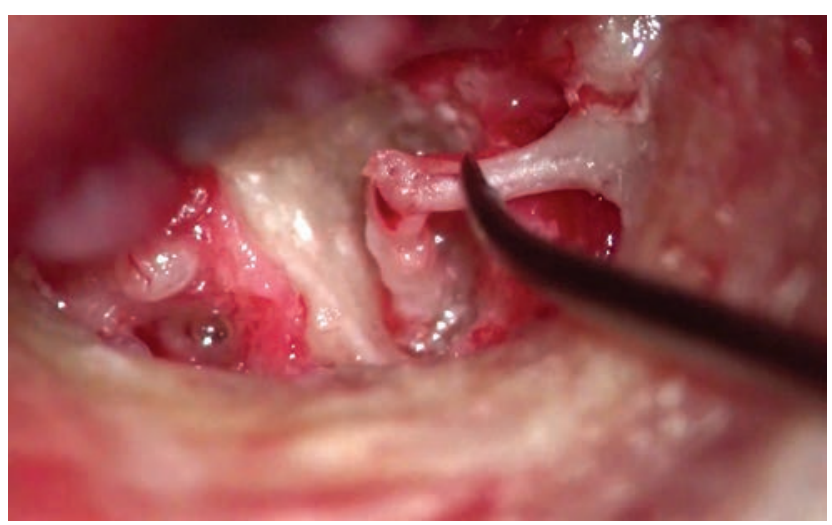

Fig. 10 Intact ossicular chain after complete clearance of granulations. 


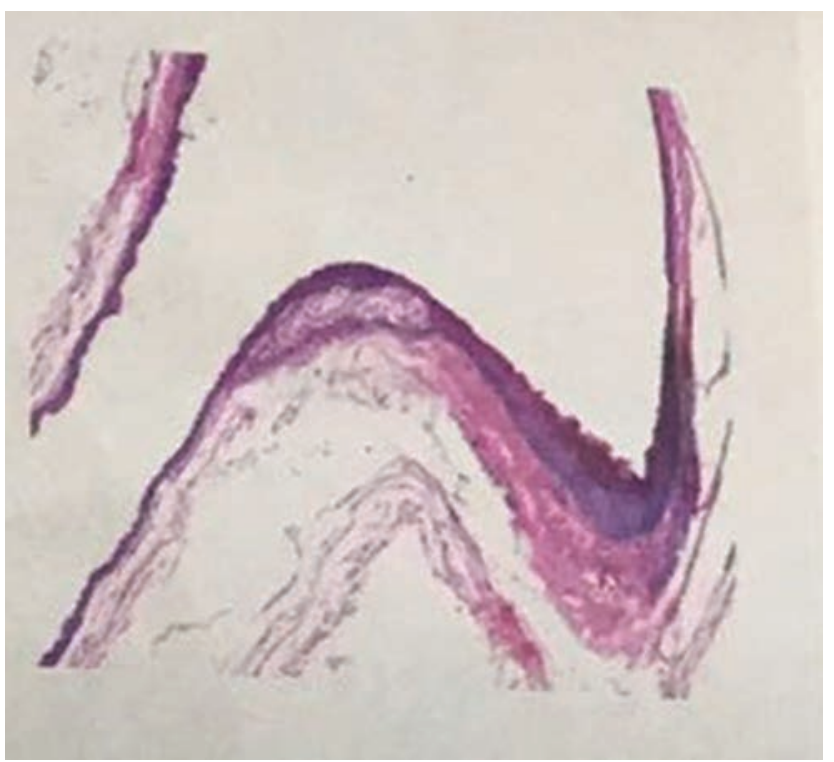

Fig. 11 Histopathological picture of biopsy of middle ear granulations.

the eustachian tube, second is hematogenous transmission from other tuberculosis foci, and third is direct implantation through the external auditory canal in perforated tympanic membrane., ${ }^{9,10,11}$ The most common features of tuberculous otitis media include minimal discharge with pale granulation tissue in the middle ear, multiple perforations in tympanic membrane, sometimes associated with facial nerve palsy, and white necrosis slough of middle ear mucosa. The patient develops rapid deterioration of hearing with more sensorineural component. They are more prone for developing profound hearing loss, if not treated timely. Because of variability in clinical presentations and lack of histopathological classical features most of the time, it is difficult to establish diagnosis. However, in case of strong clinical suspicion, even though first biopsy comes negative, one should follow up the progression and response to routine antibiotic line of management. If recovery is not satisfactory, rapid deterioration of hearing and extensive involvement of the middle ear and mastoid cavity clinically and radiologically, it is always better to explore as emergency and resend the biopsy from antrum and middle ear and complete clearance of granulations should be done to prevent further hearing loss. Antituberculosis treatment improves prognosis for most of the patients. ${ }^{12}$ Surgical treatment should always be added to medical therapy in cases of complications ${ }^{11}$ and in cases of rapid deterioration of hearing. For complete cure, medical therapy should be given at least for 9 months according to INDEX-TB guidelines provided by government of India for extrapulmonary tuberculosis.

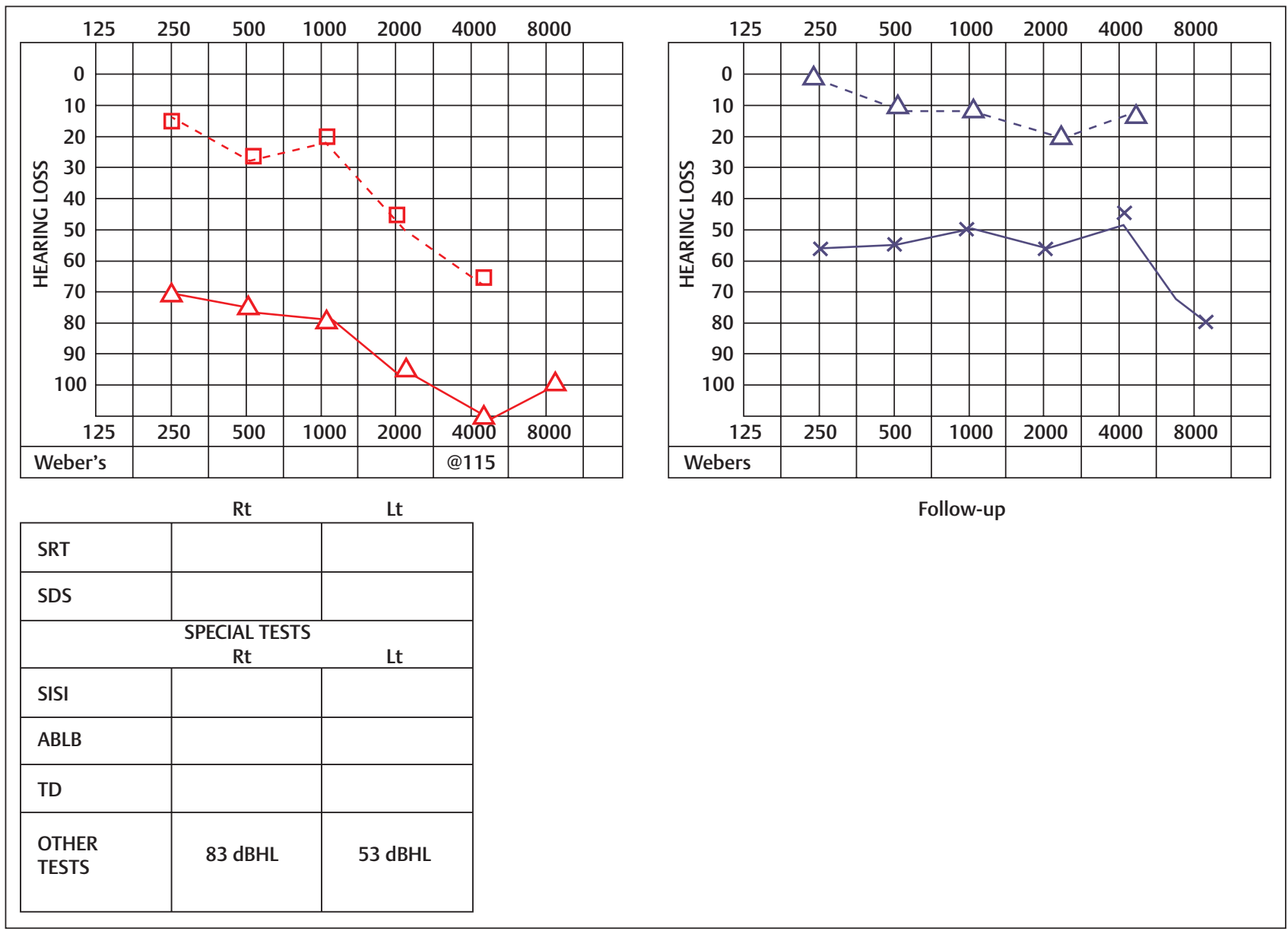

Fig. 12 Postoperative audiometry done at 3 months. 


\section{References}

1 Odetoyinbo O. Early diagnosis of tuberculous otitis media. J Laryngol Otol 1988;102(2):133-135

2 Granato L, Limae Silva LA. Tuberculous otitis media. Rev Bras Otorrinolaringol 1973;39:125-132

3 Skolnik PR, Nadol JB Jr, Baker AS. Tuberculosis of the middle ear: review of the literature with an instructive case report. Rev Infect Dis 1986;8(3):403-410

4 Plester D, Pusalkar A, Steinbach E. Middle ear tuberculosis. J Laryngol Otol 1980;94(12):1415-1421

5 Benedict RF, Cruz OLM, Morimoto E, Ramos CC, Siebert D, Miniti A. Tuberculosis of the temporal bone. Current state and presentation of 2 cases. Rev Bras Otorrinolaringol 1987;53:90-95

6 Windle Taylor PC, Bailey CM. Tuberculosis otitis media. Laryngoscope 1980;90:1039-1044

7 Sharan R, Isser DK. Primary tubersxculosis of the middle ear cleft. Practitioner 1979;222(1327):93-95
8 Vijayendra H, Parikh B. Bone conduction improvement after surgery for conductive hearing loss. Indian J Otolaryngol Head Neck Surg 2011;63(3):201-204

9 Awan MS, Salahuddin I. Tuberculous otitis media: two case reports and literature review. Ear Nose Throat J 2002;81(11):792-794

10 Chirch LM, Ahmad K, Spinner W, Jimenez VE, Donelan SV, Smouha E. Tuberculous otitis media: report of 2 cases on Long Island, N.Y., and a review of all cases reported in the United States from 1990 through 2003. Ear Nose Throat J 2005;84(8):488-490, 490, 492 passim

11 Sens PM, Almeida CI, Valle LO, Costa LH, Angeli ML. Tuberculosis of the ear, a professional disease? Rev Bras Otorrinolaringol (Engl Ed) 2008;74(4):621-627

12 Vaamonde P, Castro C, García-Soto N, Labella T, Lozano A. Tuberculous otitis media: a significant diagnostic challenge. Otolaryngol Head Neck Surg 2004;130(6):759-766 